\title{
Analisis Faktor-Faktor yang Mempengaruhi Pemenuhan Indikator Angka Kontak Komunikasi dan Rasio Peserta Prolanis di Puskesmas Kabupaten Padang Pariaman
}

\author{
Nofriyenti ${ }^{1}$, Nur Afrainin Syah ${ }^{2}$, Ali Akbar ${ }^{3}$
}

\begin{abstract}
ABSTRAK
Indikator Angka kontak komunikasi dan ratio peserta Program Pengelolaan Penyakit Kronis (Prolanis) yang merupakan dua dari tiga indikator KBKP (Kapitasi Berbasis Pemenuhan Komitmen Pelayanan), yaitu indikator angka kontak komunikasi 150 permil, indikator ratio rujukan non spesialistik $\leq 5 \%$, dan ratio peserta prolanis rutin berkunjung $\leq 50 \%$ sangat sulit sekali terpenuhi oleh Puskesmas di Kabupaten Padang Pariaman. Angka kontak komunikasi ini adalah untuk melihat aksesabilitas dan pemanfaatan pelayanan primer oleh peserta baik pelayanan di dalam gedung maupun pelayanan luar gedung. Tujuan penelitian ini adalah menganalisis faktor-faktor yang mempengaruhi pemenuhan indikator angka kontak komunikasi dan rasio peserta prolanis rutin berkunjung di Puskesmas Wilayah kerja Dinas Kesehatan Kabupaten Padang Pariaman. Penelitian ini menggunakan rancangan penelitian kualitatif jenis case study (studi kasus). Pemilihan informan dalam penelitian ini adalah secara Purposive, yang terdiri dari Kepala Dinas Kesehatan, Ketua Tim Kendali Mutu Kendali Biaya, Kepala BPJS, Kepala Puskesmas dan Penanggung jawab tekhnis pelaksanaan kapitasi Kabupaten. Hasil penelitian ini menunjukkan bahwa masih ada 3 puskesmas yang belum mampu memenuhi indikator angka kontak komunikasi $\geq 150$ permil, yaitu Puskesmas Sicincin, Puskesmas Ulakan dan Puskesmas Limau Purut. Dari tiga puskesmas tersebuat dua diantaranya yaitu Puskesmas Limau Purut dan Puskesmas Ulakan, belum mampu memenuhi indikator ratio peserta prolanis rutin berkunjung $\geq 50 \%$.
\end{abstract}

Kata Kunci: indikator, komunikasi, ratio, prolanis, puskesmas

\section{ABSTRACT}

The Communication contact number indicators of prolanis participant ratios, which are two of the three KBKP indicators, are namely communication contact number indicators of 150 per mile, non-specialist referral ratio indicator is $\leq 5 \%$ and routine visiting prolanis participants ratio is $\leq 50 \%$ that is very difficult to fulfill by the medical centre in Padang Pariaman sub district. This communication contact number was to see the accessibility and utilization of primary services by participants both services inside and services outside. The objective of this study was to analyze the factors that influence the fulfillment of communication contact number indicators and the routine prolanis participants' ratio to the medical centre in the working area of the Padang Pariaman Clinic. This study used a case study. The selection of informants in this study used purposive sampling, consisting of the Head of Clinic, the Head of the Full Quality Control Team, the Head of the BPJS, the head of the medical centre and the person in charge of the technical implementation of the district capitation. The results of this study indicated that there are still three of a medical centre that had not been able to meet the communication contact number indicator $\geq 150$ per mile, namely the Sicincin, Ulakan and Limau Purut Clinics. Two of the three clinics namely Ulakan and Limau Purut had not been able to meet the routine visiting prolanis participants' ratio $\geq 50 \%$. The

Keywords: indicators, communication, ratio, prolanis, medical center 
Affiliasi penulis: 1.Dinkes Kabupaten Padang Pariaman. 2. Bagian Patologi Anatomi Fakultas Kedokteran Universitas Andalas Padang. 3 Kementerian Kesehatan Provinsi Sumatera Barat.

Korespondensl: Nofriyenti, Email: nofriyenti81@gmail.com Telp/Hp. 081266433066.

\section{PENDAHULUAN}

Indikator angka kontak komunikasi dan ratio peserta Program Pengelolaan Penyakit Kronis (Prolanis) yang merupakan dua dari tiga indikator KBKP (Kapitasi Berbasis Pemenuhan Komitmen Pelayanan) sangat sulit sekali terpenuhi oleh Puskesmas di Kabupaten Padang Pariaman. Dilihat dari angka kontak komunikasi ini adalah untuk melihat aksesabilitas dan pemanfaatan pelayanan primer oleh peserta baik pelayanan di dalam gedung maupun pelayanan luar gedung, tanpa memperhitungkan frekuensi kedatangan peserta dalam satu bulan. Indikator ratio peserta prolanis rutin berkunjung ke puskesmas ini adalah untuk melihat kesinambungan pelayanan kesehatan terhadap masyarakat yang menderita penyakit diabetes mellitus dan hipertensi yang membutuhkan pemantauan secara terus menerus, sehingga dengan tidak terpenuhinya kedua indikator tersebut tentu akan berdampak yang tidak baik terhadap Puskesmas dalam memberikan pelayanan kesehatan. $^{1}$

Pelaksanaan penilaian KBKP di Puskesmas se Kabupaten Pariaman dimulai sejak Januari 2017. Berdasarkan hasil evaluasi dilakukan pada Triwulan I dari 25 puskesmas se Kabupaten Padang Pariaman hanya $20 \%$ yang mampu memenuhi indikator angka kontak komunikasi $\geq 150$ permil dan 32\% Indikator ratio kunjungan peserta prolanis ke puskesmas, sedangkan untuk indikator ratio rujukan non spesialistik sudah 100\%. Saat penilaian evaluasi KBKP dilakukan sampai bulan Desember 2017 masih ada 3 puskesmas yang belum mampu memenuhi indikator angka kontak komunikasi $\geq 150$ permil, yaitu Puskesmas Sicincin, Puskesmas Ulakan dan Puskesmas Limau Purut. Dari tiga puskesmas tersebuat dua diantaranya yaitu Puskesmas Limau Purut dan Puskesmas Ulakan, belum mampu memenuhi indikator ratio peserta prolanis rutin berkunjung $\geq 50 \%$, dan untuk indikator ratio rujukan non spesialistik mulai dari awal penilaian pada bulan
Januari sampai bulan Desember, sebanyak 25 Puskesmas sudah mampu memenuhinya $\leq 5 \%$. Jadi dari ketiga indikator KBKP tersebut dua indikator yaitu angka kontak komunikasi dan ratio peserta prolanis rutin berkunjung yang belum mampu terpenuhi oleh ke 25 puskesmas se Kabupaten Padang Pariaman. ${ }^{2}$

Tidak terpenuhinya dua dari ketiga indikator tersebut memperlihatkan bahwa layanan puskesmas belum menjadi pilihan yang menarik bagi masyarakat., Hal ini mengakibatkan angka kontak komunikasi akan berkurang yang berdampak pada besaran kapitasi yang diterima, sehingga dengan adanya pemotongan dana kapitasi tentu akan menganggu penganggaran baik untuk operasional, pembelian alat kesehatan serta jasa pelayanan. ${ }^{3}$

Berdasarkan data yang diambil pada salah satu Puskesmas yaitu Puskesmas Sicincin, jumlah peserta terdaftar adalah 8540 orang dengan norma kapitasi 4500 perorang. Puskesmas Sicincin menerima Rp. 38.430.000,- setiap bulannya masuk ke rekening Puskesmas, karena saat penilaian pada akhir Desember Puskesmas Sicincin tidak mampu memenuhi 1 indikator KBKP yaitu indikator angka kontak komunikasi sehingga terjadi pemotongan dana kapitasi. Dimana Puskesmas Sicincin hanya menerima 95\% setiap bulannya selama 3 bulan, kalau dilihat dari dana kapitasi yang diterima dari Rp.38.430.000,berkurang menjadi Rp.36.508.500,- setiap bulannya. Ini terlihat ada pengurangan dana sebanyak \pm Rp.2.000.000,- selama 3 bulan berturut-turut, hal ini tentu akan mengurangi pelaksanaan kegiatan operasional, pembelian alat kesehatan serta jasa pelayanan untuk puskesmas Sicincin. ${ }^{4}$

Berdasarkan uraian tersebut, peneliti tertarik untuk melakukan penelitian mengenai "Analisis faktorfaktor yang mempengaruhi pemenuhan indikator angka kontak komunikasi dan ratio peserta prolanis rutin berkunjung pada Puskesmas di Kabupaten Padang Pariaman Tahun 2017".

\section{METODE}

Penelitian ini menggunakan rancangan metode kualitatif jenis case study (studi kasus) dengan pemilihan informan secara Purposive. ${ }^{5}$ Teknik pengumpulan data dilakukan dengan wawancara 
mendalam (indepth interview), focus group discussion (FGD) dan telaah dokumen. ${ }^{6}$ Proses analisis data dalam penelitian kualitatif dilakukan pada waktu yang bersamaan dengan proses pengumpulan data berlangsung. ${ }^{6}$ Penelitian dilaksanakan pada Puskesmas di Kabupaten Padang Pariaman, yang dilaksanakan pada bulan Desember tahun 2017 sampai Maret tahun 2018.

\section{HASIL}

\section{Analisis Faktor yang Mempengaruhi Pemenuhan Indikator Angka Kontak Komunikasi}

\section{a. Kebijakan}

Hasil wawancara dengan beberapa informan terkait kebijakan pelaksanaan kapitasi berbasis pemenuhan komitmen pelayanan pada Puskesmas di Kabupaten Padang Pariaman adalah surat Edaran Bersama antara Kementrian Kesehatan Republik Indonesia dengan BPJS Kesehatan Nomor HK.03.03/ IV/053/2016 dan Nomor 01 Tahun 2016 tentang Pelaksanaan dan Pemantauan Penerapan Kapitasi Berbasis Pemenuhan Komitmen Pelayanan pada Fasilitas Kesehatan Tingkat Pertama. ${ }^{7}$

Kebijakan pelaksanaan KBK telah disampaikan

oleh BPJS Kesehatan dan Dinas Kesehatan Kabupaten Padang Pariaman kepada Puskesmas. Bimbingan tekhnis pelaksanaan juga telah dilakukan kepada Puskesmas. Kebutuhan triangulasi data mengenai kebijakan pelaksanaan kapitasi berbasis pemenuhan komitmen pelayanan disajikan hasil wawancara dengan informan lainnya yaitu ketua TKMKB cabang Padang Pariaman dan hasil focus group discussion penanggung jawab KBK di Puskesmas, yang menguatkan kebijakan pelaksanaan KBK pada Puskesmas di Kabupaten Padang Pariaman.

Pada awal implementasi pola pembayaran ini tidak semua Sumber Daya Manusia (SDM) Puskesmas siap untuk melaksanakannya. Penilaian yang dilakukan dianggap akan memberikan beban kerja tambahan, dimana untuk memenuhi kontak indikator angka kontak komunikasi saja itu pelaksanaannya harus diinput setiap hari. Pada fasilitas kesehatan tingkat pertama dan disepakati pelaksanaannya antara BPJS Kesehatan dan Dinas
Kesehatan Kabupaten Padang Pariaman. Implementasi pola pembayaran ini didasari sebagai upaya peningkatan kualitas pelayanan kesehatan di Puskesmas dan bertujuan jangka panjang sebagai upaya mencapai efektifitas dan efisiensi biaya pelayanan kesehatan. Terdapatnya sumber daya manusia di puskesmas yang tidak siap untuk menjalankannya dikarenakan persepsi akan menambah beban kerja Puskesmas.

\section{b. Sumber Daya Manusia}

Berdasarkan hasil wawancara diketahui bahwa ketersediaan sumber daya manusia di Puskesmas telah mencukupi untuk melaksanakan dan mencapai indikator angka kontak komunikasi dan ratio peserta prolanis rutin yang berkunjung, namun masih ada ketersedian sumber daya manusia yang belum mencukupi untuk memenuhi kebutuhan pencapaian dua dari tiga indikator. Dari hasil wawancara dengan Kepala Dinas Kesehatan padang Pariaman dijelaskan bahwa keterbatasan sumber daya manusia di Puskesmas ada pada ketersediaan dokter umum.

Dari hasil wawancara dengan salah satu informan, keterbatasan sumber daya manusia juga disebabkan jumlah penduduk wilayah kerja puskesmas yang cukup banyak, sehingga diperlukan upaya lebih optimal bagi puskesmas untuk mencapai indikator kapitasi berbasis pemenuhan komitmen pelayanan.

Hasil pengumpulan data melalui telah dokumen terkait dengan ketersediaan sumber daya manusia yang ada di Puskesmas diperoleh data distribusi tenaga medis dan non medis di Puskesmas dan diperhitungan ketersediaan dokter umum dengan jumlah peserta JKN yang terdaftar di Puskesmas yang masih diatas $1: 5.000$.

\section{Dana}

Berdasarkan hasil wawancara dengan informan diperoleh gambaran bahwa ketersediaan dana di Puskesmas untuk mencapai indikator AKK dan RPPRB telah mencukupi. Pendanaan yang ada di Puskesmas berasal dari APBD, APBN dan dana kapitasi peserta JKN yang dibayarkan setiap bulan melalui BPJS Kesehatan. Selain ketersediaan dana dari berbagai sumber pembiayaan, perencanaan dari 
masing-masing Puskesmas sangat berperan penting agar penggunaan dana tepat dan optimal sesuai kebutuhan Puskesmas.

Hasil pengumpulan data dari telaah dokumen dan observasi yang dilakukan pembiayaan di Puskesmas di Kabupaten Padang Pariaman terdiri dana APBD Kabupaten Padang Pariaman. Dana kapitasi dibayarkan setiap bulan sebelum tanggal 15 oleh BPJS Kesehatan berdasarkan jumlah terdaftar dikalikan besaran norma kapitasi. Penentuan besaran kapitasi berdasarkan peraturan Menteri Kesehatan No 71 tentang pelayanan kesehatan pada Jaminan Kesehatan Nasional salah satunya ketersediaan dokter umum dan dokter gigi yang ada di Puskesmas, sehingga berdasarkan ketersedian dokter umum dan dengan besaran norma kapitasi Rp. 4500 - Rp. 6000, sebagai gambaran penerimaan bulanan puskesmas se Kabupaten Padang pariaman.Ketersediaan dana di Puskesmas Kabupaten Padang Pariaman sudah mencukupi dan sejak 01 Januari 2017. Namun diperlukan perencanaan dan pengelolaan dari manajemen Puskesmas sehingga dana yang ada dapat mendukung kegiatan program Puskesmas sebagai upaya dalam pencapaian indikator KBK serta pencapaian program kesehatan lainnya. Indikator rasio peserta prolanis yang berkunjung adanya dana kegiatan dari BPJS Kesehatan yang terpisah dari dana kapitasi.

\section{d. Metode}

Hasil penelitian menunjukan bahwa tidak ada metode yang terstandar dalam pencapaian indikator KBK, masing-masing Puskesmas menyusun cara tersendiri. Namun semua Puskesmas mengacu pada metode penilaian indikator yang sudah ditetapkan melalui juknis pelaksanaan dan pemantauan penerapan kapitasi berbasis pemenuhan komitmen pelayanan pada fasilitas kesehatan tingkat pertama. Penilaian yang dilakukan setiap bulan dan rutin diumpanbalikkan ke Puskesmas bisa menjadi bahan evaluasi bagi Puskesmas jika belum mencapai zona aman, misalnya untuk puskesmas yang memiliki angka kunjungan sakit yang kecil akan meningkatkan kunjungan sehat.

\section{e. Sarana dan Prasarana}

Berdasarkan matriks triangulasi didapatkan hasil bahwa ketersediaan sarana dan prasarana di Puskesmas Kabupaten Padang Pariaman tidak menjadi kendala dalam pencapaian indikator KBK karena sudah mencukupi untuk melakukan pelayanan dan kegiatan sebagai upaya dalam mencapai ketiga indikator KBK, walaupun masih ada beberapa puskesmas yang terkendala. Sarana dan prasarana yang perlu dipersiapkan antara lain fasilitas komputer/laptop, jaringan internet, alat kesehatan dan obat yang mendukung penanganan penyakit non spesialistik.

\section{Komponen Proses}

\section{a. Perencanaan}

Dalam penelitian ini didapatkan hasil bahwa perencanaan pencapaian indikator telah dimulai sejak sosialisasi pelaksanaan KBK dilakukan dan masingmasing Puskesmas melakukan evaluasi setiap bulan sesuai dengan hasil penilaian indikator setiap bulan, namun hal ini tidak didokumentasikan secara tertulis karena sudah merupakan bagian dari rutinitas kegiatan di Puskesmas.

\section{b. Pencapaian Indikator Kinerja}

Analisis matriks triagulasi didapatkan hasil bahwa pencapaian indikator angka kontak komunikasi yang susah berada pada zona aman. Puskesmas telah melakukan berbagai upaya untuk melakukannya seperti membagi target kontak melalui kunjungan sehat pada peserta JKN-KIS yang terdaftar di Puskesmas sesuai dengan pegawai yang ada, membuat tim entrian $p$-care yang akan mengevaluasi capaian setiap minggunya. Pencapaian angka kontak diperlukan data peserta JKN-KIS yang terdaftar dan pendokumentasian nomor kartu peserta untuk $p$-care. 


\section{Aspek Output}

\section{a. Angka Kontak Komunikasi}

Dalam pelaksanaan di lapangan, Puskesmas terkendala karena tidak semua masyarakat telah memiliki kartu JKN. Peserta terdaftar di FKTP swasta, sedangkan puskesmas harus tetap menjalankan pelayanan kesehatan masyarakat. Pada puskesmas dengan luasnya wilayah kerja, keterbatasan sumber daya manusia, kecilnya pelayanan kesehatan perorangan (kunjungan sakit) namun masih tetap bisa menjadi zona aman.

Hasil penilaian AKK pada bulan Juni sampai Desember 2017 terlihat trend pencapaian angka kontak komunikasi cenderung naik dan turun. Persentase Puskesmas yang mencapai zona aman setiap bulannya hanya $40 \%$.

\section{b. Rujukan Non spesialistik}

Hasil wawancara mendalam dan focus group discussion (FGD) terhadap informan diperoleh dengan ketersediaan sarana dan prasarana serta komitmen dalam menjalankan kesepakatan dan mengisikan indikasi rujuk pada aplikasi p-care maka pencapaian rujukan non spesialistik berada pada zona aman dan prestasi.

Pencapaian indikator ini terkendala dengan perilaku peserta yang ingin langsung mendapatkan pelayanan kesehatan di Rumah sakit. Apalagi dengan dekatnya akses Rumah Sakit di Kabupaten Padang Pariaman yang menyebabkan kemudahan akses peserta, puskesmas susah menahan peserta untuk tetap dilayani di Puskesmas. Dari telaah dokumen yang dilakukan hasil penilaian rasio rujukan non spesialistik pada bulan Juni sampai Desember 2017 terlihat trend semua Puskesmas (100\%) berada pada zona aman.

\section{c. Rasio Peserta Prolanis yang berkunjung ke FKTP}

Rasio Peserta Prolanis yang berkunjung ke FKTP adalah kunjungan peserta klub prolnis diabetes melitus dan hipertensi setiap bulan untuk mengikuti kegiatan klub prolanis maupun dalam bentuk kunjungan sehat peserta klub prolanis. Hasil telaah dokumen dan yang dilakukan hasil penilaian peserta prol anis pada bulan Juni sampai Desember 2017 terlihat trend semua Puskesmas berada pada zona aman dan tidak aman. Klub Prolanis yang dikelola adalah dibetes dan hipertensi.

\section{PEMBAHASAN}

\section{Komponen Input}

\section{a. Kebijakan}

Hasil wawancara tidak jauh berbeda dengan hasil penelusuran dokumen dan pengamatan, dengan analisis triangulasi bahwa pelaksanaan Kapitasi Berbasis Pemenuhan Komitmen Pelayanan Pada Fasilitas Kesehatan Tingkat Pertama mengacu pada peraturan Menteri Kesehatan No 71 Tahun 2013, diikuti dengan Surat Edaran Bersama antara Kementerian Kesehatan Republik Indonesia dengan BPJS Kesehatan Nomor HK.03.03/IV/053/2016 dan Nomor 01 tahun $2016 .^{7}$

Adanya kebijakan ini dapat digunakan sebagai pedoman dan acuan bagi Dinas Kesehatan, BPJS Kesehatan, dan puskesmas dalam menjalankan kapitasi berbasis pemenuhan pelayanan kesehatan, serta dapat menjadi sarana monitoring dan evaluasi untuk penyempurnaan implementasinya. Dalam sosialisasi masih terdapat pegawai puskesmas yang belum siap untuk menjalankan kebijakan ini, dikarenakan pola pikir pembayaran kapitasi adalah hal yang sudah rutin diterima dengan jumlah yang tetap.

Pelaksanaan sistem pembayaran Kapitasi Berbasis Pemenuhan Komitmen Pelayanan didasari sebagai upaya meningkatkan kualitas pelayanan kesehatan di FKTP, penguat peran FKTP sebagai Gate Keeper dan tujuan jangka panjang adalah efesiensi dan efektifitas biaya pelayanan kesehatan. ${ }^{9}$

Didasarkan analisis peneliti telah adanya kebijakan pelaksanaan Kapitasi Berbasis Pemenuhan Komitmen Pelayanan dapat menjadi pedoman atau acuan bagi semua pihak yang terlibat dalam menjalankannya. Penyampaian kebijakan yang ada harus dilakukan secara bersama antara regulator, BPJS Kesehatan dan Dinas Kesehatan sebagai pembina dari Puskesmas. 


\section{b. Sumber Daya Manusia}

Dari data BPJS Kesehatan Kabupaten Padang pariaman diperoleh gambaran masih adanya kebutuhan dokter umum bagi pelayanan peserta JKN terdaftar, sehingga masih dibutuhkan 27 (dua puluh tujuh) orang dokter di Puskesmas Kabupaten Padang Pariaman. Keterbatasan jumlah sumber daya manusia seringkali dijumpai dalam sarana kesehatan pemerintah, terutama tenaga SDM untuk mendukung kelancaran proses pelayanan kepada peserta JKNKIS, namun dengan keterbatasan yang ada, sebagian besar Puskesmas tetap bisa mencapai zona aman ketiga indikator, walaupun membutuhkan upaya yang maksimal dibandingkan dengan Puskesmas lainnya.

Menurut Moeheriono (2014) manajemen berbasis kinerja merupakan suatu metode untuk mengukur kemajuan program atau aktifitas dalam mencapai hasil atau outcome yang diharapkan oleh semua pihak (stakeholders). Dengan pola pembayaran kapitasi berbasis pemenuhan komitmen pelayanan, pencapaian indikator kinerja bisa menjadi umpan balik dari pimpinan puskesmas untuk mengevaluasi kinerja pegawai dan kecukupan ketersediaan pegawai yang ada untuk mencapai target kerja di puskesmas. ${ }^{10}$

Puskesmas di Kabupaten Padang Pariaman sudah bisa mengatasi kekurangan sumber daya manusia yang ada dengan menerpkan Pola Pengelolaan Keuangan Badan Layanan Umum Daerah (PPK-BLUD). BLUD bertujuan untuk meningkatkan pelayanan kepada masyarakat dalam rangka memajukan kesejahteraan umum dan mencerdaskan kehidupan bangsa dengan memberikan fleksibelitas dalam pengelolaan keuangan berdasarkan prinsip ekonomi dan produktivitas dan penerapan praktek bisnis yang sehat. ${ }^{11}$

\section{Dana}

Berdasarkan hasil penelitian pendanaan dalam kegiatan Puskesmas sebagai upaya mencapai indikator Kapitasi Berbasis Pemenuhan Komitmen Pelayanan didukung oleh dana dari pemerintah pusat, pemerintah daerah dan dana kapitasi peserta JKN-KIS yang dibayarkan setiap bulan oleh BPJS Kesehatan. Dengan berbagai sumber dana yang ada, Puskesmas tidak mersa terkendala dalam mencapai indikator. Hal ini dapat disebabkan pengelolaan dana kapitasi dilakukan dengan mekanisme PPK-BLUD dan adanya sinergis pembiayaan dengan anggaran Pemerintah Pusat dan Pemerintah Daerah.

Pembiayaan kesehatan dalam Sistem Kesehatan Nasional 2012 bisa diperoleh dari pemerintah maupun masyarakat, bisa berupa pembiayaan kesehatan pemerintah pusat, pembiayaan kesehatan pemerintah propinsi, pembiayaan kesehatan pemerintah kabupaten/kota dan pembiayaan dari masyarakat. selain itu adanya pembiayaan dari jaminan kesehatan nasional dalam bentuk pola pembayaran kapitasi bagi peserta JKNKIS yang terdaftar di Fasilitas Kesehatan Tingkat Pertama. $^{12}$

Berdasarkan analisis peneliti sumber pendana an yang jelas, pengelolaan dana yang lancar terhadap jasa pelayanan dan biaya operasional di Puskesmas berpengaruh pada upaya pencapaian indikator angka kontak komunikasi dan ratio peserta prolanis rutin berkunjung pada Puskesmas. Untuk Kabupaten Padang Pariaman dengan penerapan PPK-BLUD memberikan dukungan bagi Puskesmas dalam mencapai indikator tersebut. Semakin tingginya harapan peran Puskesmas di era JKN sebagai gate keeper, maka Puskesmas harus memiliki kewenangan yang luas dalam mengelola pendapatan dan pengeluaran Puskesmas.

\section{d. Metode}

Berdasarkan hasil penelitian diketahui metode dalam pencapaian indikator Kapitasi Berbasis Pemenuhan Komitmen Pelayanan belum tersedia, namun Kementerian Kesehatan dan BPJS Kesehatan mengeluarkan petunjuk teknis pelaksanaan Kapitasi Berbasis Pemenuhan Komitmen Pelayanan.

Berbagai jenis pengukuran, standar dan upaya untuk meningkatkan mutu pelayanan telah tersedia dan terus berkembang. Salah satunya adalah dengan metode pembayaran berbasis komitmen pelayanan, Berdasarkan hasil evaluasi pelaksanaan kapitasi berbasis pemenuhan komitmen pelayanan tahun 2016 , terdapat adanya tantangan dan masukan yang didapatkan untuk perbaikan pelaksanaan kapitasi berbasis pada pemenuhan komitmen pelayanan. 
Sehubungan dengan hal tersebut, dilakukan pengembangan pelaksanaan kapitasi berbasis pemenuhan komitmen pelayanan tahun 2017 yang akan diberlakukan bagi seluruh Pusat Kesehatan Masyarakat, Klinik Pratama, Praktik Mandiri Dokter, dan Rumah Sakit Kelas D Pratama, sehingga pelaksanaan dan penerapan kapitasi berbasis pemenuhan komitmen pelayanan di Fasilitas Kesehatan Tingkat Pertama berjalan efektif dan efisien. $^{13}$

Hasil penelitian Hidayat (2014) menyatakan bahwa memberikan pelayanan kepada masyarakat, Puskesmas harus memiliki metode yang menunjang dalam pelaksanaan kegiatan tersebut baik berupa alat, obat-obatan dan saran penunjang medis yang membantu petugas dalam melaksanakan tugasnya dan mendukung pemberian pelayanan. ${ }^{14}$

Berdasarkan analisis peneliti metode dibutuh kan dalam pencapaian indikator angka kontak komunikasi dan ratio peserta prolanis rutin berkunjung pada Puskesmas. Petunjuk teknis yang telah ada dirasa mencukupi untuk menjadi pedoman bagi Puskesmas namun diperlukan dukungan sistem aplikasi yang memungkinkan pemantauan dilakukan oleh Puskesmas sebelum perhitungan indikator dilakukan.

\section{e. Sarana dan Prasarana}

Hasil penelitian diketahui sarana dan prasarana untuk mencapai indikator angka kontak komunikasi dan ratio peserta prolanis rutin berkunjung telah mencukupi di Puskesmas. Pengadaan sarana dan prasarana khususnya untuk menuntaskan 144 penyakit yang menjadi kompetensi layanan primer telah mencukupi. Jika Puskesmas membutuhkan penambahan, maka akan dilakukan perencanaan dan usulan ke BLUD.

Hasil penelitian ini sesuai dengan penelitian yang dilakukan oleh Sugianto (2011) yang menyatakan bahwa sarana yang mendukung dalam bekerja berhubungan dengan kinerja pegawai. Sarana dan prasarana yang baik dapat menarik minat kerja dan dapat berakibat pada produktifitas. ${ }^{15}$ Menurut Azwar (2007) dalam upaya menjaga kenyaman perlu adanya sarana dan prasarana yang mendukung sehingga dapat memberikan kepuasan kepada pasien. ${ }^{16}$

Berdasarkan analisis peneliti ketersediaan sarana dan prasarana merupakan faktor terpenting dalam mencapai indikaotr kapitasi berbasis pemenuhan komitmen pelayanan. Ketersediaan sarana dan prasarana dipengaruhi pengelolaan dana kapitasi dan pembiayaan lain yang ada di Puskesmas bisa mengakomodir kebutuhan Puskesmas secara cepat dan tepat.

\section{Komponen Proses}

\section{a. Perencanaan}

Dalam penelitian ini didapatkan hasil bahwa perencanaan pencapaian indikator telah dimulai sejak sosialisasi pelaksanaan KBK dilakukan dan masingmasing Puskesmas melakukan evaluasi setiap bulan sesuai dengan hasil penilaian indikator setiap bulan. Namun hal ini tidak didokumentasikan secara tertulis karena sudah merupakan bagian dari rutinitas kegiatan di Puskesmas. Perencanaan kinerja merupakan tahapan yang paling kritis dari keseluruhan proses manajemen kinerja. Diperlukan integrasi antara keahlian sumber daya manusia dan sumber daya lain agar mampu menjawab tuntutan perkembangan lingkungan strategis. ${ }^{10}$

Berdasarkan analisis peneliti perencanaan untuk mencapai indikator angka kontak komunikasi dan ratio peserta prolanis rutin berkunjung merupakan kegiatan strategik yang harus dilakukan dapat berupa memastikan semua kegiatan terinput di aplikasi karena penilaian akan dilakukan melalui aplikasi.

\section{b. Pencapaian Indikator Kinerja}

Hasil penelitian indikator Kapitasi Berbasis Pemenuhan Komitmen Pelayanan selama bulan juni sampai dengan desember 2017 memperlihatkan bahwa angka kontak komunikasi merupakan indikator yang paling banyak mencapai zona tidak aman. Sedangkan untuk rasio rujukan non spesialistik, semua Puskesmas bisa mencapai zona aman. Untuk Rasio Peserta Prolanis yang berkunjung ke FKTP di peroleh informasi hasil kesepakatan tim penilai belum menggunakan luran aplikasi, sehingga yang dipakai kombinasi penilaian manual dan aplikasi. 
Pengukuran kinerja merupakan suatu alat manajemen yang digunakan untuk meningkatkan kualitas pengambilan keputusan dan auntabilitas, serta untukmenilai pencapaian tujuan dan sasaran. Selain itu pengukuran kinerja juga diartikan sebagai suatu metode untuk menilai kemajuan yang telah dicapai dibandingkan dengan tujuan yang telah ditetapkan, sekaligus sebagai alat komunikasi dan alat manajemen untuk memperbaiki kinerja organisasi. ${ }^{10}$

Berdasarkan analisis peneliti pencapaian indikator Kapitasi Berbasis Pemenuhan Komitmen Pelayanan perlu dilakukan secara rutin dan menggunakan satu sumber data hasil penilaian. Penggunaan hasil pencapaian dengan kombinasi manual dan aplikasi sebaiknya ditiadakan supaya hasil pengukuran yang dilakukan bisa menjadi umpan balik bagi semua pihak yang terlibat dalam penentuan tingkat pencapaian indikator yang ditetapkan.

\section{Komponen Output}

\section{a. Angka Kontak Komunikasi}

Hasil penelitian menunjukan bahwa untuk angka kontak komunikasi masih adanya Puskesmas yang belum mencapai zona tidak aman. Hal ini disebabkan karena keterbatasan sumber daya manusia dikarenakan Puskesmas menambah jenis pelayanan, pencatatan yang belum semua kegiatan dilakukan, dan kedisiplinan sumber daya manusia di Puskesmas untuk melaporkan hasil kegiatan ke penanggung jawab pelaksanaan Kapitasi Berbasis Pemenuhan Komitmen Pelayanan.

Menurut Peraturan Menteri Kesehatan Nomor 75 tahun 2014, Puskesmas memiliki wewenang antara lain untuk menyelenggarakan Pelayanan Kesehan dasar secara komprehensif, mengutamakan upaya promotif dan preventif misalnya kunjungan rumah dapat memperluas cakupan kontak komunikasi dengan peserta JKN-KIS, tidak hanya menunggu sakit di Puskesmas atau puskesmas pembantu. Selain itu semua kegiatan yang dilakukan harus memiliki bukti kegiatan dan riwayat pelayanan kesehatan yang akan dipergunakan sebagai laporan dan evaluasi kegiatan yang sedang berjalan. ${ }^{17}$

Berdasarkan analisis peneliti pencapaian indikator angka kontak komunikasi dipengaruhi oleh perencanaan strategik puskesmas untuk meng integrasikan pelayanan perorangan dan pelayanan kesehatan masyarakat, memperbanyak kegiatan promotif dan preventif, pelaporan yang lengkap dan rutin serta kedisiplinan dalam pengumpulan hasil kegiatan dan pengentrian pada aplikasi p-care. Keterbatasan sumber daya manusia bisa tidak menjadi hambatan bagi Puskesmas dalam mencapai indikator ini jika didukung kualitas sumber daya manusia yang bagus.

\section{b. Rasio Rujukan Non Spesialistik}

Hasil wawancara mendalam dan focus group discussion (FGD) terhadap informan diperoleh dengan ketersediaan sarana dan prasarana serta komitmen dalam menjalankan kesepakatan dan mengisikan indikasi rujuk pada aplikasi p-care maka pencapaian rujukan non spesialistik berada pada zona aman dan prestasi.

Menurut Peraturan Menteri Kesehatan Nomor 5 Tahun 2014, diaharapkan dokter layanan primer dapat mendiagnosis dan melakukan penatalaksanaan secara mandiri dan tuntas. Dokter akan dapat merujuk pasien apabila memenuhi salah satu dari kriteria TACC(TimeAge-Comlicatio-Comorbidity). ${ }^{18}$

Berdasarkan analisis peneliti pencapaian indikator rasio rujukan non spesialistik dipengaruhi oleh beberapa faktor antara lain ketersediaan dokter umum di Puskesmas, kedisiplinan Puskesmas menjalankan komitmen dengan BPJS Kesehatan dalam pengentrian kriteria rujuk non spesialistik. Artinya FKTP dimungkinkan melakukan rujukan yang kriteria non spesialistik pada saat kondisi pasien yang membutuhkan kriteria rujuk (TACC).

\section{c. Rasio Peserta Prolanis Berkunjung ke FKTP}

Rasio peserta prolanis berkunjung ke FKTP masih ada 3 Puskesmas yang mencapai zona tidak aman selama penilaian bulan Juni sampai Desember 2017, rasio Peserta Prolanis berkunjung ke FKTP adalah kunjungan peserta klub prolanis diabetes dan hipertensi. Untuk Puskesmas yang belum mencapai zona aman disebabkan pemantauan yang tidak komprehensif oleh penanggungjawab terhadap peserta klub prolanis, peserta klub yang tidak setiap 
bulannya, kelengkapan dokumentasi kehadiran serta pengentrian yang tidak rutin dilakukan oleh pengelola klub pada aplikasi p-care. Terdapat 7 (tujuh) pilar pendukung kegiatan prolanis yaitu penatalaksanaan penyakit berdasarkan panduan klinis penyakit kronis, pelayanan obat secara cepat dan tepat, aktivitas fisik, edukasi, pemeriksaan penunjang, home visit dan reminder. $^{19}$

Berdasarkan analisis peneliti pencapaian indikator Rasio Peserta Prolanis yang berkunjung ke FKTP dipengaruhi oleh kontinuitas pemantauan yang dilakukan terhadap peserta klub prolanis baik berupa jenis aktivitas, dokumentasi kegiatan dan pemahaman atau pelaksanaan 7 (tujuh) pilar prolanis bagi peserta klub serta update data peserta klub prolanis di aplikasi p-care.

\section{SIMPULAN}

Terdapat beberapa kendala yang ditemukan dalam penelitian ini, diantaranya pada analisis faktor yang mempengaruhi pemenuhan indikator angka kontak komunikasi masih terkendala pada sumber daya manusia (SDM), dimana dari data BPJS Kesehatan masih adanya kebutuhan dokter umum bagi pelayanan peserta JKN terdaftar.

Pencapaian indikator angka kontak komunikasi berada pada zona aman dan tidak aman, sedangkan rasio rujukan non spesialistik semua berada di zona aman, dan Rasio Peserta Prolanis yang berkunjung pada Puskesmas berada di zona aman dan tidak aman.

\section{SARAN}

Perlu dilakukan analisis kebutuhan sumber daya manusia sesuai dengan beban kerja masingmasing Puskesmas, diantaranya ketersediaan dokter umum berdasarkan perhitungan BPJS Kesehatan.

Perlu adanya sistem pencatatan atau dokumentasi kegiatan yang terstruktur dan perencanaan strategik untuk pengintegrasian kegiatan pencapaian indikator Kapitasi Berbasis Pemenuhan Komitmen Pelayanan dengan objek peserta JKN-KIS dengan kegiatan program Puskesmas lainnya.

\section{UCAPAN TERIMA KASIH}

Terima kasih kepada semua pihak yang telah membantu dalam penelitian ini, khususnya kepada Kepala Dinas Kesehatan Kabupaten Padang Pariaman, berserta staf yang telah memfasilitasi saya untuk melakukan penelitian ini. Selanjutnya terima kasih disampaikan kepada semua pihak yang telah memberikan masukanuntuk kesempurnaan tesis ini.

\section{DAFTAR PUSTAKA}

1. BPJS Kesehatan. Peraturan BPJS Kesehatan Nomor 1 tahun 2014, tentang penyelenggaraan Jaminan Kesehatan. Jakarta: BPJS kesehatan; 2014.

2. Dinas Kesehatan Kabupaten Padang Pariaman. Profil Dinas Kesehatan Kab. Padang Pariaman tahun 2017. Padang Pariaman: Bidang Yankes; 2017.

3. Idris F. Manual Pelaksanaan JKN-BPJS Kesehat an (Info BPJS). Media Eksternal BPJS Kesehatan. 2016;(43):3-12.

4. Puskesmas Sicincin. Profil puskesmas Sicincin Kab. Padang Pariaman tahun 2017. Padang Pariaman: Puskesmas Sicincin; 2017.

5. Sugiyono. Metoda penelitian manajemen. Bandung: Alfabeta; 2014.hlm.164-415.

6. Miles MB, Huberman AM. Analisis data kualitatif. Jakarta: Universitas Indonesia Press; 2009.

7. BPJS Kesehatan. Surat Edaran bersama BPJS dan Kemenkes Rl tentang Petunjuk Teknis Pelaksanaan pembayaran kapitasi Berbasis Pemenuhan Komitmen Pelayanan pada. Fasilitas Kesehatan Tingkat Pertama. Jakarta: BPJS kesehatan; 2016.

8. Kementerian Kesehatan (Kemenkes) RI. Peraturan Menteri Kesehatan Nomor 71 tahun 2013, tentang Pelayanan Kesehatan pada Jaminan Kesehatan Nasional. Jakarta: Kemenkes RI; 2013.

9. Kemenkes RI. Peraturan Menteri Kesehatan nomor 69 tahun 2013, tentang standar tarif pelayanan kesehatan pada fasilitas kesehatan tingkat pertama dan fasilitas kesehatan tingkat lanjutan dalam penyelenggaraan jaminan kesehatan. Jakarta: Kemenkes RI; 2013. 
10. Moeheriono. Pengukuran kinerja berbasis kompetensi (edisi revisi). Bogor: Rajawali Pers; 2014.hlm.37-8.

11. Kementerian Perdagangan (Kemendag) RI. Keputusan menteri dalam negeri nomor 61 tahun 2007, tentang pengelolaan keuangan badan layanan umum daerah. Jakarta: Kemendag RI; 2007.

12. Kemenkes RI. Peraturan menteri kesehatan nomor 28 tahun 2014, tentang pengaturan pedoman pelaksanaan jaminan kesehatan nasional. Jakarta: Kemenkes RI; 2014.

13. BPJS Kesehatan. Peraturan bersama Sekjen. menteri kesehatan RI dan dirut. BPJS kesehatan nomor 02 tahun 2017, tentang petunjuk teknis pelaksanaan pembayaran kapitasi berbasis pemenuhan komitmen pelayanan pada fasilitas kesehatan tingkat pertama. Jakarta: BPJS Kesehatan; 2017.

14. Hidayat A. Pengembangan model partisipasi masyarakat dalam pelayanan kesehatan di puskesmas Kota Tangerang Selatan [tesis]. Universitas Terbuka. 2014

15. Sugianto FA. Pengaruh motivasi kerja dan gaya kepemimpinan terhadap kinerja karyawan pada PT. Madubaru Yogyakarta [skripsi]. Yogyakarta: Fakultas Ekonomi Universitas Pembangunan Nasional Veteran; 2011.

16. Azwar A. Mutu pelayanan kesehatan aplikasi prinsip lingkaran pemecahan masalah. Jakarta: Pustaka Sinar Harapan;2007.hlm.173.

17. Kemenkes RI. Peraturan menteri kesehatan nomor 75 tahun 2014 tentang standar pelayanan puskesmas. Jakarta: Kemenkes RI; 2014.

18. Kemenkes RI. Peraturan menteri kesehatan nomor 5 tahun 2014. tentang. panduan praktik klinis bagi dokter di fasilitas pelayanan. Jakarta: Kemenkes $\mathrm{Rl} ; 2014$

19. BPJS Kesehatan. Peraturan BPJS kesehatan no 1 tahun 2014 tentang penyelenggaraan jaminan kesehatan. Jakarta: BPJS Kesehatan; 2014. 